\title{
REKAYASA PERANGKAT LUNAK PRODUK INOVASI, HAK KEKAYAAN INTELEKTUAL, DAN INKUBATOR BISNIS DENGAN METODE USER CENTERED DESIGN ( Studi Kasus: Universitas Bina Darma)
}

\author{
Ifran Wahyudi ${ }^{1}$, Ari Muzakir ${ }^{2}$, \\ Mahasiswa Program Studi Sistem Informasi ${ }^{1}$, Program Studi Teknik Informatika ${ }^{2}$ \\ Universitas Bina Darma 1,2 \\ Jalan Jenderal Ahmad Yani No.3 Palembang \\ Sur-el : ifran.wahyudi@gmail.com ${ }^{1}$, arimuzakir@binadarma.ac.id ${ }^{2}$
}

\begin{abstract}
The Directorate of Innovation and Business Incubator is part of Bina Darma University which facilitates tenants to get incubations from partners who collaborate with Bina Darma University. This research was conducted with the aim of creating an information system that can solve existing problems, namely building a web-based information system and Progressive Web Apps (PWA) using the Codeigniter and Materialize framework, which is an information system designed to manage all data collection. Tenants, activity data collection, document storage, and other data in the Directorate of Innovation and Business Incubator, and can display the required information reports quickly and efficiently. By using the Focus Group Discussion (FGD) method, researchers get feedback from clients by discussing, and researchers can create systems with the best implementation to meet client needs. The results of this study are the availability of a information system that can assist users in managing all tenant data collection, activity data collection, documentation, and data on innovation products and intellectual property rights at the Directorate of Innovation and Business Incubator at Bina Darma University.
\end{abstract}

Keywords: business innovation and incubator, information system, focus group discussion, progressive web apps, materialize, codeigniter.

\begin{abstract}
Abstrak : Direktorat Inovasi dan Inkubator Bisnis merupakan bagian dari Universitas Bina Darma yang memfasilitasi para tenant untuk mendapatkan inkubasi dari para mitra yang bekerjasama dengan Universitas Bina Darma. Penelitian ini dilakukan dengan tujuan untuk membuat suatu sistem informasi yang dapat mengatasi permasalahan yang ada saat ini, yaitu membangun suatu sistem informasi berbasis web dan Progressive Web Apps (PWA) menggunakan framework Codeigniter dan Materialize, yang mana sistem informasi yang dirancang akan memanajemen seluruh pendataan Tenant, pendataan kegiatan, penyimpanan dokumen dan data-data lainnya yang ada di Direktorat Inovasi dan Inkubator Bisnis, serta dapat menampilkan laporan informasi yang diperlukan secara cepat dan efisien. Dengan menggunakan metode Focus Group Discussion (FGD), peneliti mendapatkan umpan balik dari client dengan berdiskusi, dan peneliti pun dapat membuat sistem dengan implementasi terbaik demi memenuhi kebutuhan client. Hasil dari penelitian ini yaitu tersedianya sistem informasi yang mampu membantu Pengguna dalam memanajemen seluruh pendataan tenant, pendataan kegiatan, dokumentasi, serta data-data produk inovasi dan hak kekayaan intelektual di Direktorat Inovasi dan Inkubator Bisnis Universitas Bina Darma.
\end{abstract}

Kata kunci: inovasi dan inkubator bisnis, sistem informasi, focus group discussion, progressive web apps, materialize, codeigniter.

\section{PENDAHULUAN}

Teknologi terus berkembang setiap tahunnya. Teknologi memberikan kemudahan di berbagai bidang, salah satunya pada pengelolaan informasi. Teknologi Informasi saat ini mampu menyediakan suatu sistem yang dapat mengolah data yang dimasukkan oleh pengguna dan menampilkan informasi yang dibutuhkan. Selain itu, sistem tersebut juga mampu menyimpan informasi dalam jumlah banyak secara 
terorganisir namun menghabiskan ruang fisik yang relatif kecil.

Direktorat Inovasi dan Inkubator Bisnis merupakan bagian dari Universitas Bina Darma yang memfasilitasi para tenant untuk mendapatkan inkubasi dari para mitra yang bekerjasama dengan Universitas Bina Darma. Para tenant yang ingin mengajukan data produk inovasi dan proposal bisnis nya dapat datang langsung kepada Sekretariat Direktorat Inovasi dan Inkubator Bisnis. Data tenant, mitra, dan data lainnya disimpan menggunakan Excel dan dokumen-dokumen fisik disimpan sebagai arsip di lemari arsip. Hal ini tentu sangat tidak efisien, karena lemari arsip akan bertambah setiap tahunnya, dan menjadikan pengarsipan dan pencarian dokumen arsip yang diperlukan memakan waktu yang cukup lama. Idealnya, Direktorat Inovasi dan Inkubator Bisnis dapat memanfaatkan sustu sistem informasi untuk mengkoordinir kegiatan manajemen berupa pendataan dan pengarsipan. Data-data disimpan dalam bentuk elektronik daripada bentuk fisik, sehingga menghemat ruangan yang ada. Dengan memanfaatkan sistem informasi pula, proses pencarian informasi dapat berjalan lebih cepat. Selain itu, Belum adanya suatu sistem yang dapat digunakan oleh publik untuk mencari informasi tentang kegiatan, dokumentasi, serta data-data produk inovasi dan hak kekayaan intelektual di Direktorat Inovasi dan Inkubator Bisnis Universitas Bina Darma membuat publik harus datang langsung ke Sekretariat Direktorat Inovasi dan Inkubator Bisnis Universitas Bina Darma untuk mendapatkan informasi yang dibutuhkan. Atas permasalahan ini, penelitian dilakukan dengan tujuan membuat suatu Perangkat Lunak Produk Inovasi, Hak Kekayaan Intelektual, dan Inkubator Bisnis yang dapat mengatasi permasalahan yang ada di Direktorat Inovasi dan Inkubator Bisnis Universitas Bina Darma.

\section{METODOLOGI PENELITIAN}

\subsection{Metode Penelitian}

Pada penelitian ini, digunakan metode pendekatan untuk memahami objek penelitian. Metode yang digunakan yaitu Focus Group Discussion (FGD). Teknik Focus Group Discussion (FGD) ini terdiri dari empat langkah utama, yaitu desain penelitian, pengumpulan data, analisis, dan pelaporan hasil [1]. Bahasa Permodelan yang digunakan yaitu Unifed Modeling Language (UML).

\section{Unified Modeling Language (UML)} merupakan alat bantu permodelan visual yang dapat membantu pengembang suatu sistem untuk memodelkan sistem yang akan dibuat dalam bentuk cetak biru yang baku, mudah dipahami, serta efektif untuk mengkomunikasikan rancangan sistem dengan orang lain [2]. Bahasa Permodelan yang digunakan pada penelitian ini berupa Use Case Diagram, Activity Diagram, dan Class Diagram.

\subsection{Metode Pengumpulan Data}

Untuk memperoleh data yang dibutuhkan, maka dilakukan pengumpulan data dengan metode sebagai berikut:

1) Wawancara, yaitu melakukan wawancara langsung kepada pihak Direktorat Inovasi 
dan Inkubator Bisnis, dan juga pihak lain yang terkait terhadap penelitian ini.

2) Dokumentasi, yaitu mengumpulkan dokumen-dokumen terkait penelitian ini di Direktorat Inovasi dan Inkubator Bisnis Universitas Bina Darma.

3) Studi Pustaka, yaitu melakukan penelitian kepustakaan untuk memperoleh teori-teori serta referensi yang mendukung penelitian pembuatan Perangkat Lunak Produk Inovasi, Hak Kekayaan Intelektual, dan Inkubator Bisnis ini, yang diperoleh dari buku-buku, karya ilmiah, jurnal, internet, dan sumber-sumber lain, baik dalam bentuk fisik maupun elektronik.

\subsection{Metode Pengembangan Sistem}

Metode pengembangan sistem yang diguanakan pada penelitian ini yaitu User Centered Design (UCD). Pada User Centered Design (UCD), setiap langkah proses pengembangan sistem akan dijelaskan secara singkat, diikuti dengan gagasan tentang kemungkinan dampak yang akan terjadi pada langkah tersebut [3]. Metode ini juga dapat meningkatkan nilai usability berdasarkan aspek efektivitas, efisiensi dan kepuasan pengguna. Dalam proses pengembangan aplikasi menggunakan metode UCD, terdapat beberapa tahapan yang dilakukan secara berulang, disesuaikan dengan kondisi dan kebutuhan pengguna. Adapun tahapan yang dimaksud digambarkan sebagai berikut [3].

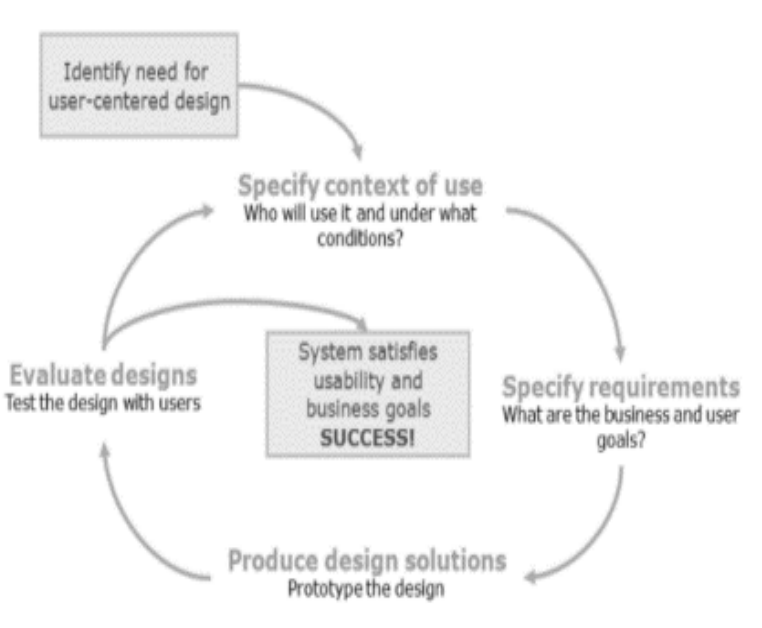

Gambar 1. Tahapan User Centered Design

\section{HASIL DAN PEMBAHASAN}

\subsection{Use Case Diagram}

Terdapat tiga aktor yang memiliki interaksi berbeda-beda terhadap sistem. Untuk menggunakan sistem, Sekretariat dan Tenant harus melalui proses login terlebih dahulu untuk menggunakan fitur-fitur sistem informasi yang sesuai dengan role akun tersebut. Pada aktor Publik, terlihat bahwa untuk berinteraksi dengan sistem, proses login tidak diperlukan, sehingga Publik dapat langsung menggunakan perangkat lunak sistem informasi untuk mendapatkan informasi yang dibutuhkan, dengan tetap mematuhi perizinan pengaksesan informasi yang telah ditetapkan untuk aktor Publik. Berikut ini merupakan Use Case Diagram untuk perangkat lunak yang dibuat. 


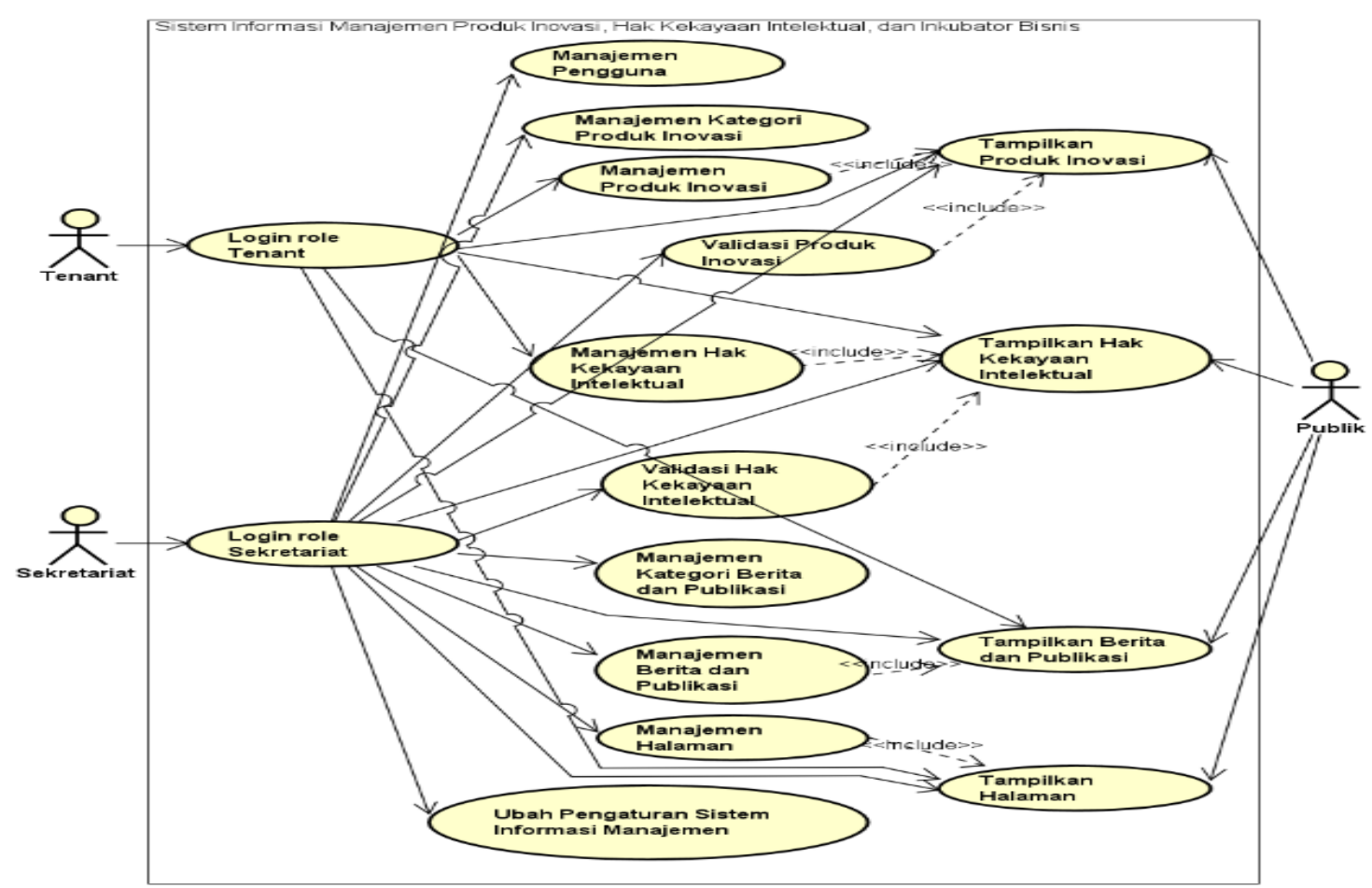

Gambar 2. Use Case Diagram

\subsection{Class Diagram}

Pada Class Diagram digambarkan tiga buah kelas utama yang berinteraksi langsung dengan pengguna beserta asosiasi nya, yang berarti kelas-kelas yang terhubung satu dengan yang lainnya. Pada asosiasi tersebut juga digambarkan hubungan yang dimiliki. Ada tiga jenis hubungan yang memungkinkan, yaitu satu ke satu (one-to-one), satu ke banyak (one-tomany), dan banyak ke banyak (many-to-many). Berikut ini merupakan Class Diagram untuk perangkat lunak yang dibuat.

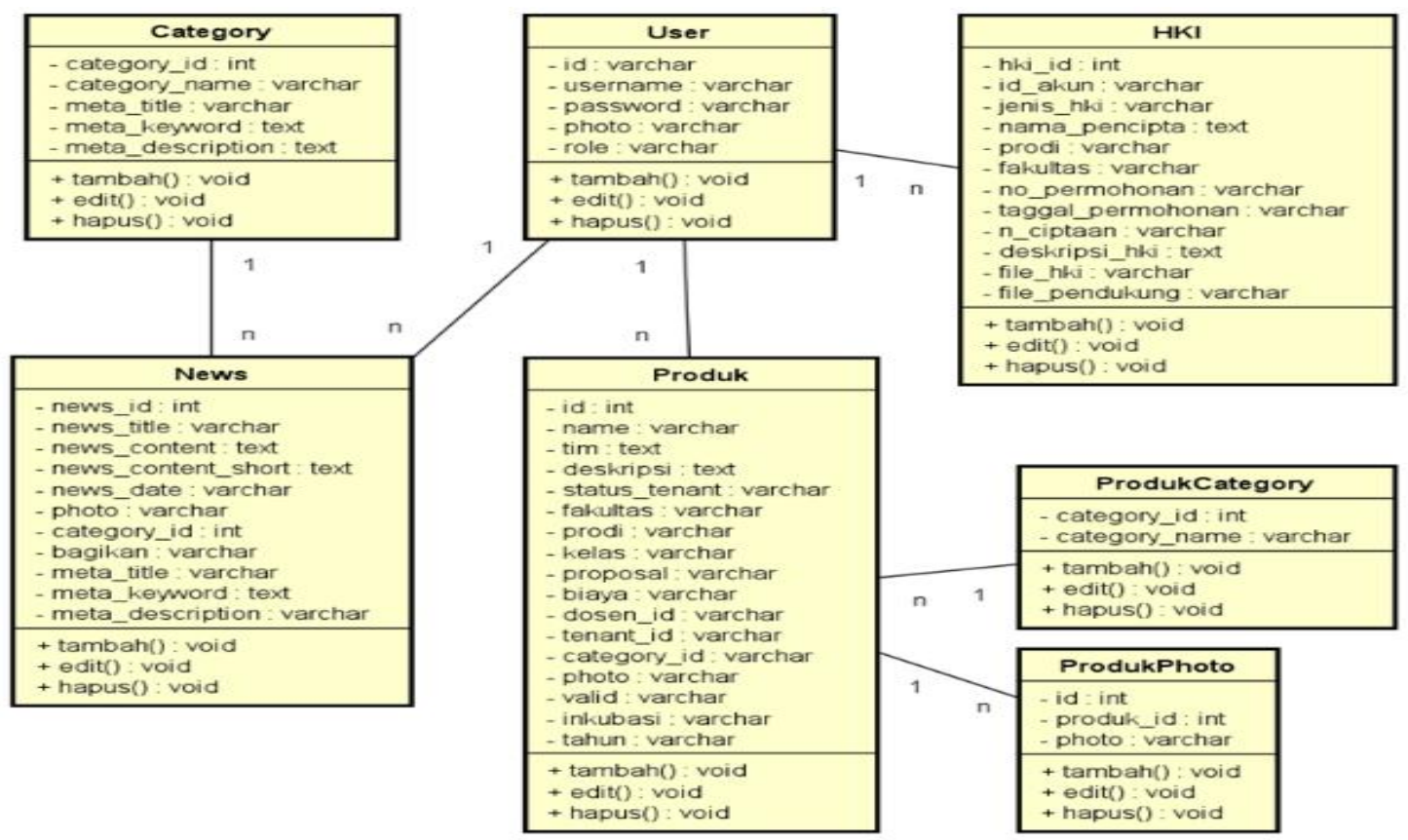

Gambar 3. Class Diagram 


\subsection{Implementasi Perangkat Lunak}

Manajemen merupakan suatu upaya yang dilakukan untuk menyelesaikan tujuan dengan menggunakan keahlian orang lain [4]. Orang lain yang dimaksud adalah bahwa seorang Manager dapat menyuruh orang lain untuk melakukan aktifitas Manajemen. Dengan adanya perangkat lunak Sistem Informasi ini, peran "orang” tersebut dapat digantikan oleh sistem ini.

Sistem yang diimplementasikan yaitu perangkat lunak yang telah mendapat feedback dari pengguna sistem. Feedback yang telah didapatkan akan digunakan untuk menyempurnakan perangkat lunak dan akan memulai kembali proses User Centered Design (UCD) hingga memenuhi aspek efektivitas, efisiensi dan kepuasan pengguna. Sistem yang diimplementasikan juga akan mendapat pembaharuan lagi saat menerima feedback pada sesi selanjutnya, hingga semua aspek tersebut dipenuhi.

Bahasa pemrograman yang digunakan untuk membangun perangkat lunak ini yaitu PHP. Bahasa pemrograman PHP dipilih karena telah terbukti banyak digunakan untuk membangun sistem informasi yang bermanfaat, contohnya pada Sistem Informasi Rekam Medis [5] dan Sistem Informasi Akademik [6].

Teknologi yang digunakan yaitu Progressive Web Apps (PWA) dan service workers. Progressive Web Apps (PWA) yaitu aplikasi web yang dapat memberikan pengalaman pengguna seperti aplikasi native pada perangkat seluler pengguna [7]. Dengan Progressive Web Apps (PWA) ini, perangkat lunak sistem informasi yang dibuat dapat memaksa rotasi layar Android menjadi landscape. Hal ini menjadikan bidang layar menjadi lebih lebar dan informasi dapat ditampilkan dengan baik. Menu untuk menambahkan Progressive Web Apps (PWA) ini akan muncul pada browser yang pengguna pakai. Teknologi ini diimplementasikan pada perangkat lunak yang dibuat dimaksudkan agar perangkat lunak ini tidak hanya dapat digunakan pada desktop, melainkan berbasis cross-platform, yaitu dukungan perangkat lunak pada device dan sistem operasi yang berbeda-beda, yang diharapkan dapat memberikan kemudahan dalam penggunaan perangkat lunak pada smartphone atau gadget lainnya yang berbasis mobile [8].

Saat pengguna memasuki sistem informasi, akan ditampilkan halaman beranda. Halaman ini berisi navigasi yang dapat digunakan oleh pengguna untuk berpindah ke menu yang diinginkan.

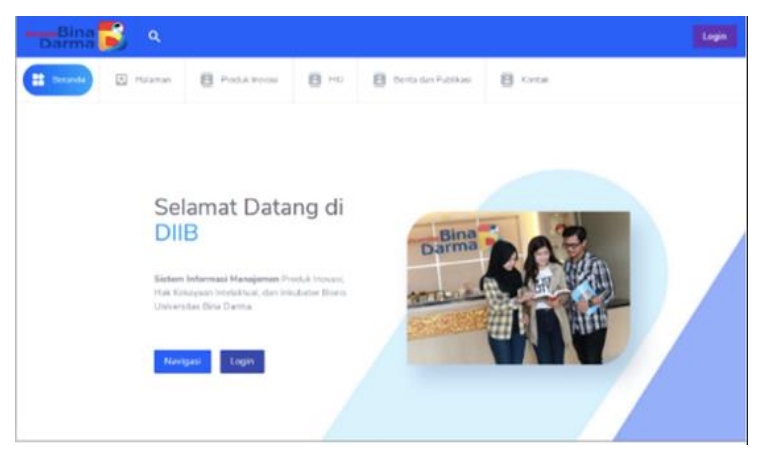

\section{Gambar 4. Tampilan Beranda}

Selanjutnya halaman Berita dan Publikasi. Halaman ini berisi tentang berita dan publikasi yang diterbitkan oleh Direktorat Inovasi dan Inkubator Bisnis Universitas Bina Darma secara publik.

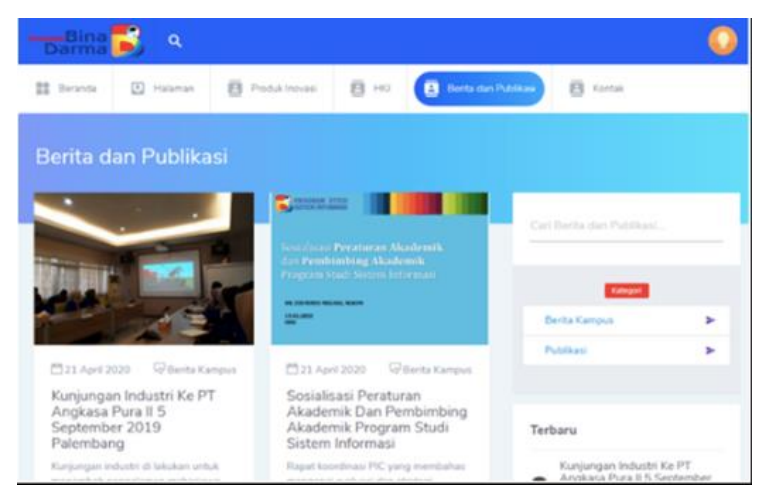

Gambar 5. Tampilan Berita dan Publikasi 
Pada halaman Produk Inovasi, akan ditampilkan informasi produk inovasi apa saja yang ada, beserta detail produk inovasi tersebut. Halaman ini berisi informasi produk inovasi yang tersedia secara publik.

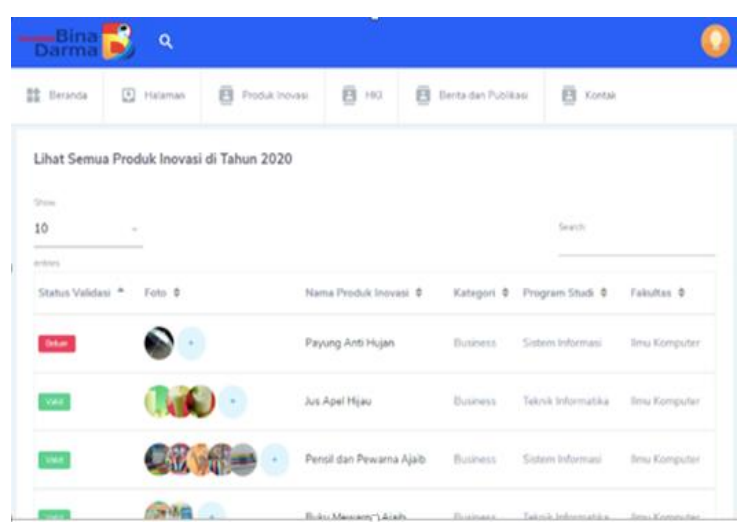

Gambar 6. Tampilan Produk Inovasi

Begitu pula pada halaman Hak Kekayaan Intelektual, akan ditampilkan informasi hak kekayaan intelektual apa saja yang ada, beserta detail hak kekayaan intelektual tersebut. Halaman ini berisi informasi hak kekayaan intelektual yang tersedia secara publik.

Terdapat tiga role, yaitu Sekretariat, Tenant, dan Publik. Berikut ini penjelasan lengkap tiap pengguna.

\section{a. Sekretariat}

Sekretariat pada sistem informasi ini adalah mahasiswa ataupun mahasiswi magang yang dapat melakukan manajemen informasi di Direktorat Inovasi dan Inkubator Bisnis. Kebutuhan Sekretariat pada Perangkat Lunak Produk Inovasi, Hak Kekayaan Intelektual, dan Inkubator Bisnis Universitas Bina Darma yaitu sebagai berikut:

(1) Sekretariat dapat masuk kedalam sistem informasi dengan menggunakan username dan password.

(2) Sekretariat dapat melihat informasi total produk inovasi yang terdaftar, total hak kekayaan intelektual yang terdaftar, total berita dan publikasi yang telah disimpan, serta total pengguna yang terdaftar. Informasi ini tersedia pada halaman depan saat sekretariat masuk ke dalam sistem.

(3) Sekretariat dapat memanajemen produk inovasi semua pengguna, termasuk manajemen kategori produk inovasi.

(4) Sekretariat dapat memanajemen hak kekayaan intelektual semua pengguna.

(5) Sekretariat dapat memanajemen berita dan publikasi, termasuk manajemen kategori berita dan publikasi.

(6) Sekretariat dapat memanajemen semua pengguna yang terdaftar di sistem informasi ini, termasuk data akun seketariat itu sendiri.

(7) Sekretariat dapat memanajemen semua halaman yang ada, yaitu halaman tentang, halaman galeri foto, halaman tim, dan halaman kontak.

(8) Sekretariat dapat mengubah pengaturan website.

b. Tenant

Tenant pada sistem informasi ini adalah mahasiswa ataupun mahasiswi Universitas Bina Darma, baik individu ataupun ketua dari suatu kelompok Tenant, yang merupakan pemilik Produk Inovasi serta Hak kekayaan Intelektual yang ingin mendaftarkan Produk Inovasi serta Hak kekayaan Intelektual yang dimiliki ke Direktorat Inovasi dan Inkubator Bisnis Universitas Bina Darma. Kebutuhan Tenant pada Perangkat Lunak Produk Inovasi, Hak Kekayaan Intelektual, dan Inkubator Bisnis Universitas Bina Darma yaitu sebagai berikut:

(1) Tenant dapat masuk kedalam sistem informasi dengan menggunakan username dan password. 
(2) Tenant dapat mengubah data akun yang dimilikinya, yaitu foto dan password.

(3) Tenant dapat melihat informasi total produk inovasi yang didaftarkannya dan total hak kekayaan intelektual yang didaftarkannya. Informasi ini tersedia pada halaman depan saat Tenant masuk ke dalam sistem.

(4) Tenant dapat memanajemen produk inovasi yang dimilikinya.

(5) Tenant dapat memanajemen hak kekayaan intelektual yang dimilikinya.

(6) Tenant dapat melihat produk inovasi semua pengguna.

(7) Tenant dapat melihat hak kekayaan intelektual semua pengguna.

(8) Tenant dapat melihat berita dan publikasi.

(9) Tenant dapat melihat semua halaman yang ada, yaitu halaman tentang, halaman galeri foto, halaman tim, dan halaman kontak.

c. Publik

Publik pada perangkat lunak sistem informasi ini adalah masyarakat umum yang ingin mencari informasi tentang Berita dan Publikasi, Produk Inovasi, serta Hak kekayaan Intelektual yang terdaftar di Direktorat Inovasi dan Inkubator Bisnis Bisnis Universitas Bina Darma. Kebutuhan Publik pada Perangkat Lunak Produk Inovasi, Hak Kekayaan Intelektual, dan Inkubator Bisnis Universitas Bina Darma yaitu sebagai berikut:

(1) Publik dapat menggunakan sistem informasi tanpa menggunakan username dan password.

(2) Publik dapat melihat produk inovasi semua pengguna.

(3) Publik dapat melihat hak kekayaan intelektual semua pengguna

(4) Publik dapat melihat berita dan publikasi.
(5) Publik dapat melihat semua halaman yang ada, yaitu halaman tentang, halaman galeri foto, halaman tim, dan halaman kontak.

Pada penjelasan diatas, terlihat bahwa ketiga aktor tersebut memiliki interaksi yang berbeda-beda terhadap sistem. Untuk menggunakan sistem, Sekretariat dan Tenant harus melalui proses login terlebih dahulu untuk menggunakan fitur-fitur sistem informasi yang sesuai dengan role akun tersebut. Pada aktor Publik, proses login tidak diperlukan sehingga Publik dapat langsung menggunakan sistem informasi untuk mendapatkan informasi yang dibutuhkan, dengan tetap mematuhi perizinan pengaksesan informasi yang telah ditetapkan untuk aktor Publik ini.

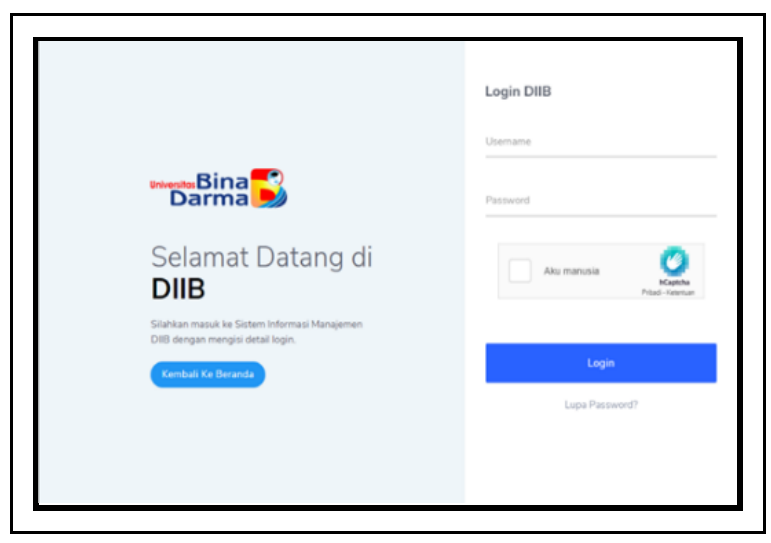

\section{Gambar 7. Tampilan Login}

\section{KESIMPULAN}

Dari penelitian yang dilakukan untuk pembuatan Perangkat Lunak Produk Inovasi, Hak Kekayaan Intelektual, dan Inkubator Bisnis Universitas Bina Darma ini, telah diambil beberapa kesimpulan. Pertama, perangkat lunak sistem informasi yang ada mampu menyediakan sistem yang dapat membantu Pengguna dalam memanajemen seluruh pendataan Tenant, pendataan kegiatan, dokumentasi, serta data-data 
produk inovasi dan hak kekayaan intelektual di Direktorat Inovasi dan Inkubator Bisnis Universitas Bina Darma. Kedua, informasi yang diperlukan dapat ditampikan dengan cepat dan tepat dengan implementasi fitur pencarian yang baik dan terbaru, sehingga pencarian informasi dapat dilakukan dengan menggunakan berbagai kata kunci yang terkait dan dapat menampilkan informasi yang tepat dengan sangat cepat, bahkan hampir tanpa jeda. Ketiga, tersedianya sistem informasi yang dapat diakses oleh pengguna yang terdaftar, yaitu Sekretariat dan Tenant, juga Publik yang membutuhkan informasi tentang kegiatan, dokumentasi, serta data-data produk inovasi dan hak kekayaan intelektual di Direktorat Inovasi dan Inkubator Bisnis Universitas Bina Darma. Dan yang terakhir, sistem informasi dapat digunakan dengan mudah, memiliki tampilan yang menarik, cepat, dan juga aman, sehingga meningkatkan daya saing Direkorat Inovasi dan Inkubator Bisnis Universitas Bina Darma. Perangkat lunak sistem informasi ini dapat diakses dimana saja dan kapan saja dengan mendukung multi perangkat, sehingga Pengguna dapat mengakses informasi dimanapun dan kapanpun selama perangkat yang digunakan terhubung ke internet.

\section{DAFTAR PUSTAKA}

[1] T. O.Nyumba, K. Wilson, C. J. Derrick, dan N. Mukherjee, "The use of focus group discussion methodology: Insights from two decades of application in conservation," Methods Ecol. Evol., vol. 9, no. 1, hlm. 2032, Jan 2018, doi: 10.1111/2041210X.12860.

[2] Munawar, Analisis perancangan sistem berorientasi objek dengan UML (Unified
Modelling Language). Bandung: Informatika Bandung, 2018.

[3] R. Heimgärtner, "ISO 9241-210 and Culture? - The Impact of Culture on the Standard Usability Engineering Process," dalam Design, User Experience, and Usability. User Experience Design Practice, vol. 8520, A. Marcus, Ed. Cham: Springer International Publishing, 2014, hlm. 39-48.

[4] D. Darmawan dan K. N. Fauzi, SISTEM INFORMASI MANAJEMEN. Bandung: PT REMAJA ROSDAKARYA, 2013.

[5] N. Sopiah dan A. Muzakir, "PENGGUNAAN METODE TCSD (TASK CENTERED SYSTEM DESIGN) DALAM WEBSITE REKAM MEDIS PADA RUMAH SAKIT PELABUHAN PALEMBANG," hlm. 12.

[6] A. Muzakir, Asmura, dan Afriyudi, "IMPLEMENTASI OBJECT ORIENTED HYPERMEDIA DESIGN METHOD PADA SISTEM INFORMASI AKADEMIK SMK MADYATAMA," hlm. 10, 2017.

[7] S. S. Tandel dan A. Jamadar, "Impact of Progressive Web Apps on Web App Development," vol. 7, no. 9, hlm. 7, 2018.

[8] A. Muzakir, "Prototyping Aplikasi E-Health sebagai Bagian Pengenalan Obat-Obatan Dengan Teknologi Cross- Platform," $J$. Inform., hlm. 6, 2018. 